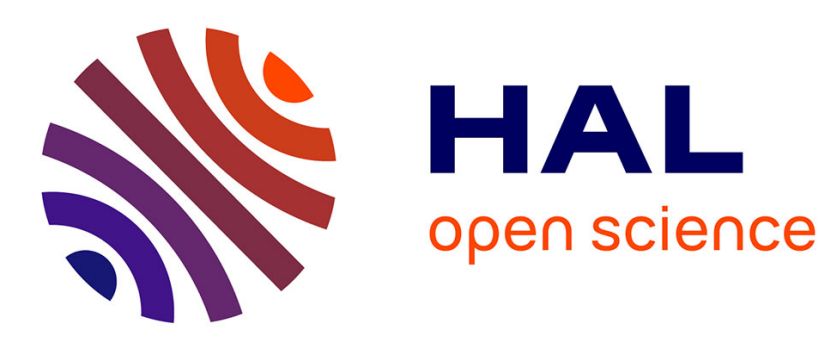

\title{
Clean Carrier Cores for Electrophotography
}

T. Mochizuki

\section{- To cite this version:}

T. Mochizuki. Clean Carrier Cores for Electrophotography. Journal de Physique IV Proceedings, 1997, 07 (C1), pp.C1-577-C1-580. 10.1051/jp4:19971237 • jpa-00254922

\section{HAL Id: jpa-00254922 https://hal.science/jpa-00254922}

Submitted on 1 Jan 1997

HAL is a multi-disciplinary open access archive for the deposit and dissemination of scientific research documents, whether they are published or not. The documents may come from teaching and research institutions in France or abroad, or from public or private research centers.
L'archive ouverte pluridisciplinaire HAL, est destinée au dépôt et à la diffusion de documents scientifiques de niveau recherche, publiés ou non, émanant des établissements d'enseignement et de recherche français ou étrangers, des laboratoires publics ou privés. 


\title{
Clean Carrier Cores for Electrophotography
}

\author{
T. Mochizuki
}

Advanced Technology Laboratory, FDK Corporation, 2281, Washizu, Kosai-Shi, Shizuoka 431-04, Japan

\begin{abstract}
Most carrier cores for electrophotography are made from $\mathrm{Cu}-\mathrm{Zn}$ or $\mathrm{Ni}-\mathrm{Zn}$ ferrites. But in recent years, the use of these materials has been restricted by environmental regulations in many countries. In answer, we have developed clean carrier cores from environmentally friendly magnetic materials. One such material is magnetite, which we at FDK Corporation mass-produce by using an original production method. This magnetite has single phase and high-purity properties. The other is clean ferrite, which is a new non-hazardous composite magnetic material designed to meet customers' strict requirements.
\end{abstract}

\section{INTRODUCTION}

Soft ferrite carrier cores have been used in two-component developers for printers and photocopiers in large quantities. But environmental experts are now warning that these carriers, when placed in waste disposal sites after use, may be contaminating underground water: The experts explain that the nickel, copper, zinc and other hazardous heavy-metal ions disperse from the thrown-away soft ferrite carriers into the soil at waste disposal sites when exposed to acid rain; even if a waste disposal site has a concrete casing that seals itself off from the surrounding soil, heavy-metal ions can infiltrate into underground drinking water through cracks in the concrete. As a result, state of California in USA established a strict regulation regarding hazardous heavy-metal ions in water, and various governments followed suit.

Three approaches are conceivable in meeting these regulations in the case of ferrite carrier cores ("carrier cores" are interchangeably called "carriers" in this paper). First, ferrite carriers may be replaced by iron powder-an approach taken in the case of carriers for some high-speed monochromatic electrophotographic equipment. Second, ferrite carriers may be replaced by magnetite cores, which are applicable to medium and medium/high-speed monochromatic equipment. Third, ferrite carrier materials may be replaced by non-hazardous magnetic materials. Despite the time required for research and development, machine makers are particularly eager to see new non-hazardous carrier materials developed for preserving a clean environment.

\section{CARRIER CORES}

\subsection{FDK's Carrier Cores}

We have developed environmentally "clean carriers" that meet the environmental regulations of all countries. These clean carriers can be classified into magnetite $\left(\mathrm{Fe}_{3} \mathrm{O}_{4}\right)$ and clean ferrites. Magnetite is produced by using FDK's original manufacturing method. Clean ferrites are made only from non-hazardous metals and oxygen, and are designed to exhibit electromagnetic characteristics that resemble those of soft ferrites.

Carrier cores supplied by FDK can be classified into the following types: 


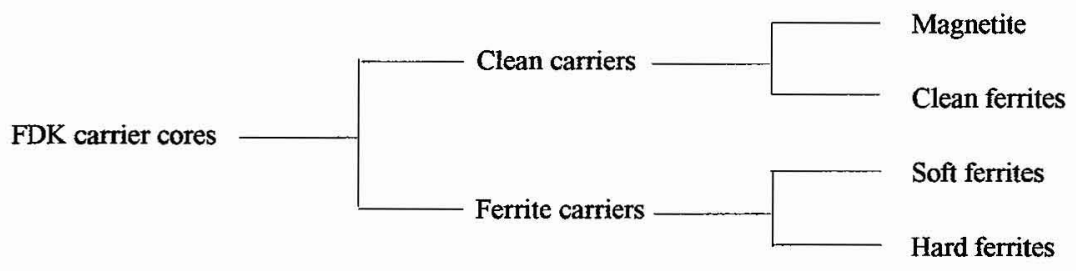

\subsection{Magnetite}

To produce magnetite, we perform reduction and sintering of hematite $\left(\mathrm{Fe}_{2} \mathrm{O}_{3}\right)$ by the reactive sintering method. The reduction process has two separate stages. The first involves an incomplete combustion of polyvinylalcohol (PVA), which is the reducing agent, in a nitrogen gas. The second involves the utilization of a thermal balance based on the iron oxide phase and oxygen concentration. Figure 1 shows a flow chart of our magnetite production.

The main characteristics of our magnetite are: 1) single phase, 2) high purity, and 3) no reducing gases. High purity is an especially important property. Our magnetite is virtually pure and free from alkaline metal content, so that its electric characteristics are extremely stable, thus ensuring high electrophotographic equipment performance.

\subsection{Clean Ferrites}

\subsubsection{Material Design}

After magnetite, the remaining category of our clean carriers is the clean ferrite, which takes into account the following requirements:

1) Must be exclusively made from non-hazardous materials;

2) Must permit control of the magnetization;

3) Must allow control of resistivity in relation to the electric field strength.

As used above, "control" means that we can design and produce clean carriers having the exact electromagnetic characteristics we intend to obtain. This controllability is essential for the development of advanced electrophotographic equipment.

Figure 2 shows the categories of conventional ferrites. While the use of $\mathrm{Ni}, \mathrm{Cu}$ and $\mathrm{Zn}$ metals is restricted by environmental regulations, these three elements are extremely important in obtaining carrier cores suitable for electrophotography. Ni is expensive but has a superb magnetic characteristic. Having a relatively low melting point, $\mathrm{Cu}$ and $\mathrm{CuO}$ allow us to change the surface porosity of the core to a great extent. $\mathrm{Zn}$ helps to achieve high magnetization levels. We have tested a wide variety of non-hazardous single-phase ferrites that lacked all of the three elements, and failed to obtain from any experimental ferrite a favorable characteristic that was equivalent to those of conventional $\mathrm{Cu}-\mathrm{Zn}$ ferrites.

Consequently, we designed composite magnetic ceramics to obtain clean ferrites that have characteristics equivalent to those of $\mathrm{Cu}-\mathrm{Zn}$ ferrites. A non-hazardous ferrite was adopted to provide a magnetic phase, while a non-hazardous metallic oxide was selected to provide a electrical resistance phase. We attempted to control the electromagnetic characteristics of the composite magnetic ceramics by changing the ratio and distribution of the two phases.

Since clean ferrites are composite materials, their internal stress was believed to be greater than that of conventional $\mathrm{Cu}-\mathrm{Zn}$ ferrites. Accordingly, clean ferrites have a relatively large coercive force. The plural-phase sometimes shows the decreasing of granular strength and the difference of the composition of each particles. But our clean ferrite didn't show the both wrong tendency. Although we observed a segregation of elements inside each particle of a clean ferrite, similar segregation occurs in the particles of $\mathrm{Cu}-\mathrm{Zn}$ ferrites as well. In $\mathrm{Cu}-\mathrm{Zn}$ ferrites, the segregation of $\mathrm{Cu}$ elements is caused by a melting and recrystallization of $\mathrm{CuO}$.

We noted that magnetization adjustment is another important factor related to the plural-phase state of clean ferrites. Due to their small coercive force and relatively angular $\mathrm{M}-\mathrm{H}$ curves, $\mathrm{Cu}-\mathrm{Zn}$ ferrites have magnetization that are not significantly affected by magnetic field strength. In contrast, clean ferrites have a relatively large coercive force and circular $\mathrm{M}-\mathrm{H}$ curves, since they contain non-magnetic ingredients. So the magnetization of clean ferrites vary widely according to the magnetic field strength. We therefore magnetized clean ferrites by a magnetic field of $1 \mathrm{kOe}$ strength - not by saturation magnetization -in order to obtain a characteristic comparable to those of $\mathrm{Cu}-\mathrm{Zn}$ ferrites. 
As a result, we succeeded in developing the five different categories of clean ferrites that are shown in Table 1 , along with their magnetic and resistance phases.

\subsubsection{Production Methods and Characteristics}

As an example, we shall explain the Mg-category clean ferrite that we developed (Figure 3). Its basic ingredients were hematite and $\mathrm{Mg}$ materials, which were wet-milled in a mixture with water. After PVA was added as a binder and reducing agent, the mixture was granulated into spherical shapes by a spray dryer. The resultant pellets were sintered and reduced in a nitrogen gas, and were finally surface-treated by reduction or oxidation for the adjustment of resistance.

For clean ferrites made of composite materials, it is particularly important to equalize each carrier core particle. By applying the EPMA (Electron Prove Micro Analysis) technique, we selected the optimal mixing condition for the equal distribution of elements in each particle. The X-ray diffraction patterns of the $\mathrm{Mg}$-category clean ferrites indicated the existence of three phases: the spinel phase of magnetite and $\mathrm{Mg}$ ferrite, hematite phase and MgO phase. The spinel phase was a magnetic phase, while the other two were resistance phases. Thus we confirmed that our $\mathrm{Mg}$-category clean ferrites had properties that were as originally designed at the material selection stage.

Characteristics of our clean ferrites are:

1) They are designed to the exact specifications of our customers;

2) These new composite magnetic materials are different from conventional ferrites;

3) They contain no hazardous elements.

Since magnetization and resistivity of clean ferrites are in a trade-off relation, it is impossible to control them separately. We were able to obtain values of magnetization from 0 to $90 \mathrm{emu} / \mathrm{g}$, depending on the value of resistivity that was variable from $10^{3}$ to $10^{11} \mathrm{ohm} \cdot \mathrm{cm}$. Table 2 shows the major magnetic characteristics of clean ferrites. Table 3 compares the production costs of clean ferrites and $\mathrm{Cu}-\mathrm{Zn}$ ferrites.

\section{CONCLUSION}

At FDK Corporation, we have succeeded in developing clean carrier cores that meet the environmental regulations of all countries. These clean carriers can be divided into magnetite and clean ferrites, both of which are produced by FDK's original production techniques. In particular, clean ferrites are new composite magnetic materials that can be designed to suit our customers' specific needs. We are hopeful that clean ferrites will become the main material of electrophotographic carrier cores in the near future.

\section{Acknowledgments}

We are greatly indebted to the enlightening discussions with Mr. I. Sasaki, and our thanks are also extended to Mr. Y. Mano, Mr. T. Tomozawa, Mr. A. Shimokawa, and Mr. T. Nakano for their cooperation in the experiments with and the production of carrier core test samples.

\section{References}

[1]Y.Mano, A.Shimokawa, T.Mochizuki and I.Sasaki, Ceramic transactions Volume 47(1995) pp.261-268.

[2]U.S.A Patent No.5512195. 


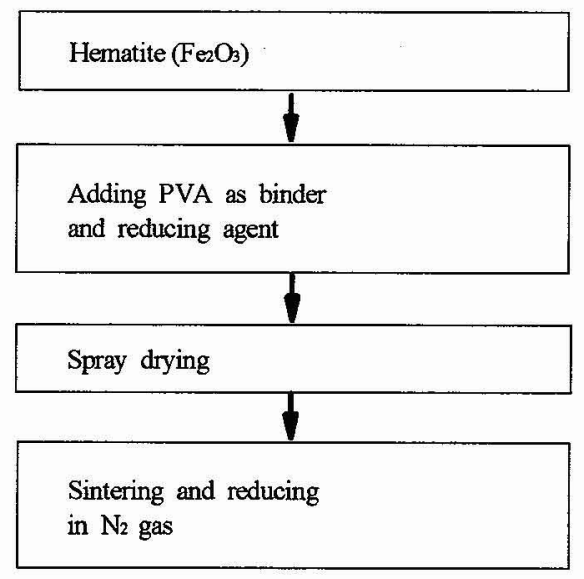

Fig.1 FDK magnetite production method.

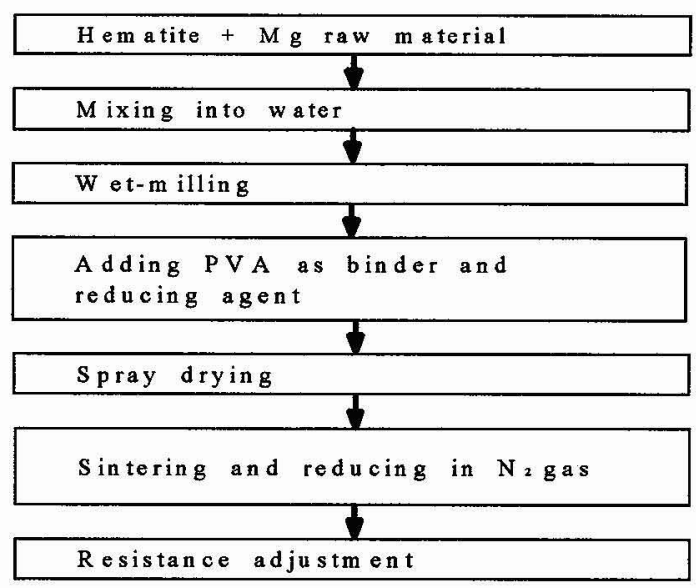

Fig.3 Mg-category clean ferrite production method.

Table.2 Typical characteristics of clean ferrites

\begin{tabular}{|c|c|c|c|}
\hline $\begin{array}{l}\text { Clean } \\
\text { ferrites }\end{array}$ & $\begin{array}{l}\text { Magnetization } \\
\text { at } 1 \mathrm{kOe} \\
{[\mathrm{em} \mathrm{u} / \mathrm{g}]}\end{array}$ & $\begin{array}{l}\text { Coersive } \\
\text { force } \\
\text { [Oe] }\end{array}$ & $\begin{array}{l}\text { Resistivity } \\
\text { at } 100 \mathrm{t} / \mathrm{cm} \\
{[G \cdot 0 \mathrm{hm} \cdot \mathrm{cm}]}\end{array}$ \\
\hline Magnetite & 67 & 12 & 0.2 \\
\hline Ti-category & 51 & 35 & 2.2 \\
\hline Ca-category & 44 & 57 & 3.5 \\
\hline Mg-category & 55 & 14 & 6.5 \\
\hline M n-category & 58 & 4.5 & 1.4 \\
\hline Li-category & 54 & 3.0 & 1.0 \\
\hline Cu-Zn ferrite & 63 & 2.0 & 1.0 \\
\hline
\end{tabular}

Non-hazardous ferrites

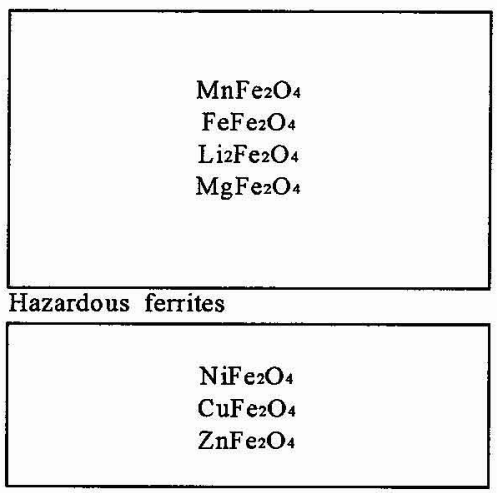

Fig. 2 Major ferrite categories.

Table.1 Clean ferrites.

\begin{tabular}{|l|l|l|}
\hline & Magnetic phase(s) & Resistance phase(s) \\
\hline Ti-category & $\mathrm{FeFe}_{2} \mathrm{O}_{4}$ & $\begin{array}{l}\mathrm{Fe}_{2} \mathrm{O}_{3} \\
\mathrm{TiO}_{2}\end{array}$ \\
\hline Ca-category & $\begin{array}{l}\mathrm{FeFe}_{2} \mathrm{O}_{4} \\
\text { Mg-category }\end{array}$ & $\begin{array}{l}\mathrm{FeFe}_{2} \mathrm{O}_{4} \\
\mathrm{MgFe}_{2} \mathrm{O}_{4}\end{array}$ \\
\hline Mn-category & $\begin{array}{l}\mathrm{FeFe}_{2} \mathrm{O}_{4} \\
\mathrm{MnFe}_{2} \mathrm{O}_{4}\end{array}$ & $\begin{array}{l}\mathrm{Fe}_{2} \mathrm{O}_{3} \\
\mathrm{MgO}\end{array}$ \\
\hline Li-category & $\begin{array}{l}\mathrm{FeFe}_{2} \mathrm{O}_{4} \\
\mathrm{Li}_{2} \mathrm{Fe}_{2} \mathrm{O}_{4}\end{array}$ & $\begin{array}{l}\mathrm{MeO}_{2} \mathrm{O}_{3} \\
\mathrm{Me}_{2} \mathrm{O}_{3} \\
\mathrm{Li}_{2} \mathrm{O}\end{array}$ \\
\hline
\end{tabular}

Table. 3 Manufacturing cost of clean ferrites

\begin{tabular}{|c|c|c|}
\hline & $\begin{array}{l}\text { Clean } \\
\text { ferrites }\end{array}$ & $\begin{array}{l}\text { Conventional } \\
\text { Cu-Zn } \\
\text { ferrites }\end{array}$ \\
\hline Raw material & (ᄋ) & $x$ \\
\hline Sintering & $x$ & 0 \\
\hline $\begin{array}{l}\text { Resistance } \\
\text { adjustment }\end{array}$ & $\begin{array}{c}\Delta \\
\text { Necessary or } \\
\text { Not necessary }\end{array}$ & $\begin{array}{cc}\text { Not } & \text { necessary }\end{array}$ \\
\hline Total cost & 0 & 0 \\
\hline
\end{tabular}

(O) Low cost 0 : Average cost $\times$ : High cost 